DOCTRINA

\title{
Biopolítica y verdad: El caso de Marchiafava-Bignami en el dispositivo judicial chileno
}

\author{
Biopolitics and truth: The case of Marchiafava-Bignami disease \\ in the Chilean criminal apparatus
}

\author{
Ricardo CAMARgo Brito
}

Universidad de Chile

\author{
Nicolás Ried Soto \\ Universidad de Chile
}

\begin{abstract}
RESUMEN Enmarcado en las perspectivas biopolíticas, y en particular en el bioderecho, este trabajo analiza la recepción que, por medio de tecnologías de neuroimágenes, realiza el «dispositivo» judicial chileno desde un régimen de verdad establecido por un determinado saber científico. Se destaca que el proceso de traducción judicial tiende a darse de manera amplificada, examinándose particularmente el caso de un sujeto afectado por la enfermedad de Marchiafava-Bignami (EMB), un extraño síndrome neuronal que tiene por efecto principal el impulso a consumir bebidas alcohólicas. Se analiza una sentencia de la Corte de Apelaciones de Santiago de Chile que acoge dicho diagnóstico, produciendo de manera performativa una modalidad de vida que no es tratada como mera excepción, sino como una forma de vida excusada.
\end{abstract}

PALABRAS CLAVE Biopolíticas, bioderecho, régimen de verdad, Marchiafava-Bignami, vida performativa.

ABSTRACT Within the framework of biopolitical perspectives, and especially bio-law, this paper analyses the reception that, through technologies of neuroimaging, the Chilean juridical apparatus gives place from a regimen of truth established by a given scientific knowledge. The paper highlights that the process of juridical translation seems to take place in an enlarging way, and examines the juridical case of an individual affected by the Marchiafava-Bignami disease (EMB), a very rare neuronal affection that has as a main effect the irresistible impulse of alcohol consumption. It is analyzed a sentence of the Appeal Court of Santiago of Chile that accepts the diagnostic of EMB disease, giving 
place to a way of life which is not treated as a mere exception in a performativity sense, but as a form of excused life. .

KEYWORDS Biopolitics, biolaw, regime of truth, Marchiafava-Bignami, performativity life.

\section{La emergencia del biopoder molecular}

La captura de la vida biológica por parte del poder político puede ser considerada un rasgo fundante de la modernidad. Es cierto que en otras épocas históricas, como lo documenta Michel Foucault en Obrar mal, decir la verdad (2014) y Giorgio Agamben en El reino y la gloria (2008), la constitución del sí ha sido el objetivo de diversas tecnologías sociales. No obstante, es sólo a partir del siglo XVIII que la vida en su sustrato biológico ha comenzado a ser objeto de una intensa y especializada intervención gubernamental, ejercida por autoridades estatales y no estatales (Rose, 1989). Ello ha ocurrido tanto a nivel del cuerpo de los individuos por medio de técnicas disciplinarias, como también a nivel de la especie humana o población a través de técnicas de regulación o biopolíticas. Aparte de las obras canónicas que Foucault nos ha legado a este respecto, existe un cúmulo extenso de literatura que ha explorado tanto el vector disciplinar como el regularizador de lo que en conjunto podemos llamar el paradigma del biopoder contemporáneo (véase Castro, 2011a: 55-56; 2011b: 52; Lemke, Casper y Moore, 2011: 36; Nealon, 2008: 45; Reid, 2011; Revel, 2008: 36; Taylor, 2011: 44-45).

Sin embargo, y como se ha sostenido en la literatura reciente (Camargo y Ried, 2016: 89), a partir del último cuarto del siglo XX, con el desarrollo de las ciencias de la vida y en particular con los avances de la neurociencia y la genética, se da lugar a una nueva etapa de mayor intensidad y extensión de una específica modalidad del biopoder que hemos caracterizado como «biopoder molecular», esto es, un poder que ya no sólo disciplina los cuerpos de los individuos o regulariza las poblaciones, sino que aspira a escrutar e intervenir la dimensión molecular de los individuos, sus códigos genéticos y sus circuitos neuronales, y a partir de ahí regular la vida desde su gestación o incluso a crear nuevas vidas gobernadas desde sus dimensiones moleculares.

La literatura que documenta esta etapa contemporánea del biopoder molecular es abundante (véase Armstrong, 1983, 1995; Arney y Bergen, 1984; Clarke y otros, 2003; Engelhardt, Stuart y Towers, 1979; Feinstein, 1967; Starr, 1982) y, aunque poco sistematizada, muestra con claridad que a pesar de encontrarse en una etapa inicial y en la mayor parte de los casos reviste un carácter experimental, las técnicas de biopoder molecular comienzan a extenderse de manera peculiar más allá de los circuitos propios de la investigación científica y a alcanzar la intervención médica (véase Rose, 1985, 1989, 1996, 1999, 2007; Rose y Miller, 2008; Rose y Abi-Rached, 2013; Franklin, 1995, 2000, 2005). 
Se trata de un fenómeno de traducción de técnicas de intervención desarrolladas al principio en la biológica molecular, en particular genética y neuronal, a ámbitos aplicados de la vida social, fundamentalmente médica, pero también relativa a la práctica criminológica o de control de conductas indeseadas, con todas las implicancias políticas, éticas y jurídicas que ello conlleva (véase Aggarwal, 2009; Aharoni y otros, 2013; Aharoni y otros, 2008; Arrigo, 2007). En otras palabras, asistimos a un proceso de expansión de las técnicas de biopoder molecular que buscan regular la vida biológica de los individuos desde sus constituciones moleculares hasta el control de las poblaciones, pasando por la disciplina de sus cuerpos (Camargo y Ried, 2016: 89).

\section{Régimen de verdad científica y régimen de verdad judicial}

Uno de los ámbitos de la sociedad en que se ha desplegado este biopoder molecular es el derecho, y en particular las prácticas de litigación judicial.

Ello ocurre porque el campo jurídico es un ámbito en donde las traducciones del saber científico al mundo social encuentran una consagración formal más expedita, precisamente debido a las singularidades y exigencias de la práctica judicial. ${ }^{1}$ Esta fue una cuestión advertida tempranamente por Michel Foucault, quien en 1973 dictó un ciclo de conferencias en la Universidad Católica de Río de Janeiro, en las que examinaba la relación entre el poder y la verdad, en específico en función del derecho. Esas conferencias, agrupadas en la publicación La verdad y las formas jurídicas, muestran una manera de comprender la verdad no como una sustancia del saber anterior a toda práctica humana, sino como lo contrario: un efecto de las prácticas sociales «inventadas» de forma estratégica y polémica. Foucault da valor a las prácticas jurídicas, en especial a las judiciales, pues asume que el análisis histórico de ellas en cuanto prácticas sociales permite localizar de mejor manera nuevas formas de subjetividad. Lo que a Foucault le interesa es destacar cómo el derecho construye la verdad políticamente, mediante un modo de producción que no sitúa su mirada en la relación saber-poder, como sí en las prácticas sociales, en sus propias palabras: «Me pareció que entre las prácticas sociales, cuyo análisis histórico permite localizar la formación de nuevas formas de subjetividad, las prácticas jurídicas o, más concretamente, las prácticas judiciales están entre las más importantes» (Foucault, 2010: 489). Este posicionamiento de la verdad como un efecto es principal para Foucault: analiza la producción de regímenes de verdad de la Grecia clásica en función de la figura del juramento presente en La Ilíada de Homero, en contraposición de la figura del testigo-cualquiera que aparece en Edipo rey de Sófocles, como también la figura

1. Estas traducciones han ido históricamente desde la introducción de técnicas de detección de mentiras hasta la consagración formal de informes periciales como medios de prueba válidos. En Chile, el informe pericial como medio de prueba está establecido en el Código de Procedimiento Civil desde 1902. 
premoderna de las ordalías y los rituales sagrados de determinación de la verdad en la Edad Feudal. Esa historia que traza Foucault hasta la división de poderes del Estado y el surgimiento de un poder judicial le permite configurar una noción política de la verdad que él denomina exterior, constituida por prácticas sociales y disputas que se organizan de manera polémica y estratégica, diferente de una noción interior de la verdad que se relaciona con un cierto saber científico que se corrige a partir de sus propios principios de regulación (Foucault, 2010: 489-490). Esa es la división dual de la verdad que Foucault entiende desde la historia de la ciencia, que articula una cierta historia de aquello que es verdadero desde la construcción de sus propias reglas internas, frente a lo que podríamos ilustrar con el conjunto de dispositivos jurídicos que construye verdades sobre determinados objetos en función de este aspecto externo, Foucault se centra en los rituales del «testigo» que jura decir la verdad sobre el ganador de una carrera descrita por Homero en su Ilíada. Que el aspecto sea interno dice relación con el hecho de discriminar si algo entra o no en el juego de reglas dado, mientras que el hecho que sea externo muestra la capacidad de dar forma a la realidad que tienen los dispositivos judiciales. Por ello es interesante preguntarse por la relación entre estos dos aspectos (Foucault, 2010: 502-504).

Bajo la noción de una historia exterior de la verdad, que tiene en cuenta «el problema de la formación de una serie de campos del saber a partir de relaciones de fuerza y de relaciones políticas existentes en la sociedad» (Foucault, 2010: 500), es que podemos preguntarnos por la cuestión de la verdad formal que el dispositivo judicial produce en alianza con otros dispositivos, como los relacionados a la ciencia, y cuestionar de esa manera la distinción que Foucault realiza entre una historia exterior e interior de la verdad: ¿no es acaso que existe una imbricación entre ambas maneras de producir la verdad?

Tengamos en cuenta que el sistema judicial penal produce una verdad formal en función de una relación triple entre quien acusa, quien es acusado y quien resuelve. En esta relación, la figura del defensor es la que proporciona argumentos en favor de quien es imputado por algún tipo de infracción normativa, y los tipos de argumentos a los que recurre contemplan también aquéllos de carácter científico. En términos del problema expuesto por Foucault, la verdad que emite el tribunal mediante la sentencia tiene como insumos un conjunto de presupuestos de saber, en la forma de racionalidades y tecnologías, que configuran un determinado poder. La novedad radica en que ese poder no se manifiesta exclusivamente sobre lo que el tribunal diga respecto del derecho vigente, sino también se extiende a un decir la verdad sobre la vida de los individuos, produciéndose una relación específica entre el dispositivo de la verdad y el biopoder. 


\section{Saber científico, saber judicial y técnicas de intervención molecular (neuroimágenes)}

Esta tensión entre saber-verdad científico y saber-verdad jurídico se ha expresado en una extensa literatura reciente que ha documentado la recepción de diversas técnicas de intervención neuronal (imágenes de resonancia magnética funcional y no funcional, tomografías cerebrales, specter, etcétera) en la litigación judicial de las judicaturas anglosajonas. ${ }^{2}$ Estas investigaciones han enfocado sus esfuerzos en analizar los impactos estrictamente jurídicos, a saber: nuevos medios probatorios de la expresión fidedigna de la verdad de las personas (por ejemplo, detectores de mentiras neuronales), medios probatorios para eximir o exculpar responsabilidad penal o civil (imágenes neuronales) y control preventivo de la delincuencia (marcadores neuronales), entre otros. ${ }^{3}$

Sin embargo, ha habido poco análisis referido a mutaciones experimentadas por la conducta de los individuos que, al ser objeto de intervención molecular sancionada por la verdad formal propia del dispositivo judicial, alcanza en los hechos mutaciones singulares que van más allá incluso de las determinaciones acotadas generadas en la investigación científica, pues «operan» como verdades actualizadas que gobiernan lo que hacen o dejan de hacer los individuos. Esto es, se da lugar a nuevas «formas de vidas» ofrecidas al campo social y político mediante la sanción emitida por los regímenes de verdad judicial, todo lo cual ocurre en avenidas muy distintas a las que se constituyen en el campo científico o en las esferas propias del debate público tradicional.

En nuestro país, las modalidades e intensidades en que las técnicas de biopoder molecular han sido acogidas en la litigación judicial son aún ignoradas. Este artículo es probablemente el primer trabajo que, basado en una investigación empírica más amplia, busca reflexionar, a partir de un caso específico de recepción de dicho biopoder (la recepción de la enfermedad de Marchiafava-Bignami), en torno a la tensión producida entre saber científico y jurídico y su impacto en los contornos de las definiciones operativas de la vida.

\section{Caso de Marchiafava-Bignami en Chile}

En 2003, la Corte de Apelaciones de Santiago dicta una sentencia que tiene por acusado a un abogado y notario por el delito reiterado de manejo en estado de ebriedad. ${ }^{4}$ La defensa alega que la conducta del imputado debe ser eximida de responsabilidad

2. La recopilación más actualizada de dicha literatura está contenida en el sitio web de la MacArthur Foundation Research Network on Law and Neuroscience, disponible en http://bit.ly/2kU63qk.

3. Una buena recopilación se encuentra en Catley y Claydon (2015).

4. Sentencia de Corte de Apelaciones de Santiago, rol 11.811-2001, 11 de julio de 2003. 
penal, en función de los requerimientos del Código Penal, del artículo 11 número 1, en relación con la eximente del artículo 10 número $1 .{ }^{5}$ Se trata de una estrategia judicial que ha sido ya reiteradamente acogida por la jurisprudencia, pero que en el caso en comento presenta una peculiaridad adicional. ${ }^{6}$

En efecto, el tribunal sostiene que el alcoholismo no es una causa independiente de la voluntad, pues el acusado decidió de manera voluntaria ingerir alcohol, y tampoco es una eximente para conducir, pues el estado de ebriedad no priva de razón de modo tal que el imputado no puede alegar que no estuvo en sus manos la decisión de conducir o no. ${ }^{7}$ Sin embargo, la defensa alega que el acusado sí estaba en un estado mental que implicaba que el hecho de ingerir alcohol no puede ser asumido como un acto completamente voluntario. Mediante un informe de resonancia nuclear magnética (RNM), que añade una evaluación «neuropsicológica», alega que sus funciones cognitivas presentaban un deterioro significativo. En específico, sostiene que el imputado está afectado por la enfermedad de Marchiafava-Bignami. La enfermedad de Marchiafava-Bignami (EMB) es «una entidad de muy baja frecuencia de distribución mundial en la que se produce desmielinización tóxica progresiva y necrosis del cuerpo calloso con extensión ocasional a la sustancia blanca subcortical adyacente, asociada principalmente al consumo crónico de bebidas alcohólicas» (Ar-

5. Artículo 11 del Código Penal: «Son circunstancias atenuantes: 1.a) las expresadas en el artículo anterior, cuando no concurren todos los requisitos necesarios para eximir de responsabilidad en sus respectivos casos [...] Artículo 10: Están exentos de responsabilidad criminal: 1) el loco o demente, a no ser que haya obrado en un intervalo lúcido, y el que, por cualquier causa independiente de su voluntad, se halla privado totalmente de razón».

6. Esta relación en que la circunstancia no funciona como excluyente de responsabilidad, pero sí como atenuante de la misma, ha sido confirmada por la jurisprudencia chilena en: Corte Suprema, 2 de octubre de 1936, G. 1936, segundo semestre, número 84, página 343; Corte Suprema, 21 de agosto de 1959, R.T. LVI, segunda parte, sección cuarta, página 182; Corte de Talca, 13 de febrero de 1933, G. 1935, primer semestre, número 85, página 353; Corte de Temuco, 6 de marzo de 1935, primer semestre, número 116, página 570, R.C.P., tomo 1, página 237; Corte de Concepción, 27 de octubre de 1938, G. 1938, segundo semestre, número 119, página 526; Corte de Valparaíso, 31 de diciembre de 1940, G. 1940, segundo semestre, número 88, página 401; Corte de Talca, 4 de junio de 1948, G. 1948, primer semestre, número 62, página 325; Corte de Santiago, 9 de junio de 1951, R. T XLVIII, segunda parte, sección cuarta, página 89; Corte de Santiago, 12 de agosto de 1951, R.T XLVIII, segunda parte, sección segunda parte, sección cuarta, página 151.

7. Considérese como antecedente doctrinario que la norma del artículo 10 número 1 proviene del Código Penal Español de 1850, y fue discutido por la comisión redactora del código chileno en 1873. En un intento por excluir las circunstancias de delirium tremens por la excesiva ingesta de alcohol, se acordó que los alcohólicos quedaban privados de razón por causas voluntarias, como son la ingesta de alcohol. Tesis reforzada por la doctrina, acotando que si bien los casos de privación total de la razón por causa de embriaguez no sirven como argumento de eximente de responsabilidad, sí sirven como razón jurídica de atenuante que contempla el artículo 11 número 1 (Labatut, 1976: 133-135; Novoa Monreal, 1960: 46-482; Etcheberry, 1970: 198-199; Cousiño Mac Iver, 1992: 198-199; Garrido Montt, 2007: 217; Politoff, Matus y Ramírez, 2004: 299). 
belález y otros, 2003: 156). La enfermedad «fue descrita por primera vez en 1903 por dos patólogos italianos, Marchiafava y Bignami, quienes la diagnosticaron mediante un estudio histopatológico en tres pacientes alcohólicos italianos consumidores de vino tinto, quienes fallecieron luego de haber presentado estado convulsivo y coma» (Arbelález y otros, 2003: 156).

Lo significativo de la introducción del diagnóstico de la enfermedad de Marchiafava-Bignami al caso judicial en cuestión es que la traducción de verdades producidas desde el saber científico al saber jurídico formal es más intensa y fuerte que las establecidas en el campo científico. En efecto, los estudios científicos de la enfermedad aludida a menudo mencionan degeneraciones neuronales generales, sin entrar a precisar cómo y en qué grado ello afectaría la voluntad de los enfermos. Al respecto, los trabajos científicos que refieren a esta enfermedad distinguen tres estados degenerativos con sus efectos sintomatológicos respectivos, pero sin referirse a las consecuencias específicas sobre la conducta o formas de comportamiento de los pacientes:

La evolución puede ser aguda, subaguda o crónica. En la forma aguda los pacientes pueden presentar convulsiones, coma y muerte. En la subaguda pueden sobrevivir varios años con un cuadro demencial, disartria e hipertonía de las extremidades o presentar recuperación parcial. La forma crónica se manifiesta por un síndrome de desconexión y demencia progresiva (Arbelález y otros, 2003: 158).

A su vez, en sede judicial se despliega un dispositivo que da lugar a la ampliación de veridicción antes aludida y que incluye al menos las siguientes etapas:

- Saber científico: Verdad científica (EMB).

- Operacionalización: Técnicas de «mostramiento» neuromolecular (RMN).

- Racionalización: Traducción de verdad científica (razonamiento judicial).

- Determinación: Establecimiento de verdad jurídica ampliada.

- Actualización: Despliegue de los contornos de la nueva vida creada.

- Nueva modalidad de vida:Vida excusada sancionada por circuitos neuronales patologizados.

En efecto, los jueces se refieren en primer lugar a la enfermedad en su sentencia y destacan el impacto específico que ella tuvo en la conducta del imputado.

En tal sentido, la Corte de Apelaciones de Santiago sostuvo que la enfermedad provoca una compulsión a beber. La argumentación es indirecta, pero no por ello menos conclusiva y extensiva para la determinación de la conducta del acusado. El considerando undécimo de la sentencia de la Corte señala en tal sentido:

Que en lo que dice relación con la atenuante denominada «eximente incompleta» contenida en el artículo 11 número 1 del Código Penal, cabe volver, en primer 
término, a recordar las características de esta enfermedad, dentro de las cuales debe destacarse la inclinación a efectuar actos anormales, pudiendo considerarse como tal la comisión de ilícitos penales, ya que lo normal es que las personas traten de no incurrir en ellos.

Lo anterior, sumado a la reiteración de ilícitos semejantes en el tiempo, algunos con días de diferencia, hacen presumir un grado de personalidad anómala, lo que se encuentra ratificado por los informes periciales evacuados por el Instituto Médico Legal, a fojas 88 y a fojas 171 , los cuales son concordantes y concluyentes en cuanto a la existencia de una imputabilidad disminuida. Por lo anterior, se acogerá la circunstancia modificatoria de responsabilidad penal contenida en el artículo 11 número 1 del Código Penal. ${ }^{8}$

Más aún, la Corte recuerda que si bien la intoxicación etílica es una eximente de responsabilidad cuando se da en ciertas circunstancias no atribuibles al imputado, en el caso del notario y abogado en cuestión se alude a una enfermedad degenerativa que se debería controlar terapéuticamente reduciendo el consumo de alcohol y evitando que el acusado conduzca vehículos motorizados. Ello en atención a que el delito de consumo en estado de ebriedad, en el caso en comento, fue cometido en tres ocasiones entre 2001 y 2003. En consecuencia, el tribunal rechazó en primer término la exención de responsabilidad completa, aunque sí redujo la imputabilidad en base a las atenuantes que consagra el Código Penal, esto es, como una eximente incompleta. Esto se condice con lo sostenido por los tribunales españoles, e incluso con las discusiones a propósito de la redacción del más reciente Código Civil de España, donde se pretendía incluso asimilar la EMB con la embriaguez letárgica, la enfermedad de Korsakov, e incluso la demencia (Mateo Ayala, 2006: 136).

El punto relevante es advertir cómo la Corte de Apelaciones de Santiago ha admitido una técnica de intervención neuronal (resonancia nuclear magnética, a fojas 88 y fojas 171), con lo que produjo un triple efecto. En primer lugar, se da lugar a la recepción de un saber científico muy específico que vincula una determinada imagen neuronal con un diagnóstico médico de una condición previamente clasificada en el saber científico: la enfermedad de Marchiafava-Bignami. En ello, sin embargo, la Corte de Apelaciones chilena no hace más que seguir una tendencia creciente en la jurisprudencia comparada que ha acogido este tipo de tecnologías de neuroimágenes en juicio. ${ }^{9}$

En segundo lugar, se realiza la operación de traducción de ese saber científico a un nuevo marco de saber-hacer constituido por la verdad jurídica-formal propia del dispositivo judicial. Es en esta operatoria donde ocurren expansiones singulares de

8. Sentencia de Corte de Apelaciones de Santiago, considerando undécimo.

9. El uso de técnicas de neuroimagen para la detección y diagnóstico de la EMB es recurrente en la literatura especializada, véase Hillbom y otros (2014). 
la verdad proveniente del campo científico que finalmente van a impactar las modalidades de vida de los individuos intervinientes. En el caso en cuestión, la traducción se expresa a partir del razonamiento judicial. Primeramente, como dijimos antes, se rechaza la causal de eximente de responsabilidad total, pero se acoge como una eximente incompleta (artículo 11, inciso primero del Código Penal).

Cabe advertir que el razonamiento de la Corte encuentra su legitimidad enunciativa en el saber científico importado y traducido a través de los informes periciales, evacuados por el Instituto Médico Legal, referidos a los exámenes de resonancia magnética nuclear (RMN) que «muestran» la patología médica aludida: la enfermedad de Marchiafava-Bignami. En tal sentido, la RMN actúa como título de veridicción proveniente del campo científico (medicina nuclear), el que sin embargo es ampliado en sus impactos hacia ámbitos más allá de lo habitualmente aceptado por el saber científico. En efecto, es en esta ampliación de veridicción donde se ve desplegada toda la potencialidad de este nuevo biopoder molecular, pues, aunque la sentencia legisla para el caso particular, sus efectos prácticos son más generales. Nos referimos a la sanción de una modalidad de vida singular que no existía antes de dicha operación. En el caso en cuestión, lo que se inaugura es una modalidad de vida excusada (parcialmente) por medio de una referencialización a un circuito neuronal anormal o patologizado, el que puede ser «mostrado» a través de RMN y por tanto evidenciado en su objetividad, más allá de toda duda (incluso sobrepasando las indeterminaciones propias del saber-científico). La manera en que ocurre dicha ampliación de veridicción, en los términos de la propia Corte, es, en primer lugar, estableciendo un estándar de comportamiento «normal»:

Las características de esta enfermedad, dentro de las cuales debe destacarse la inclinación a efectuar actos anormales, pudiendo considerarse como tal la comisión de ilícitos penales, ya que lo normal es que las personas traten de no incurrir en ellos. ${ }^{10}$

Vemos entonces desplegado un proceso gestacional que en seis etapas formalizadas da lugar performativamente a una nueva modalidad de vida, a partir de una práctica judicial fundamentada en una práctica científica. En términos de la distinción que realizaba Foucault, podemos afirmar que el sistema judicial acepta como verdadera una nueva modalidad de vida dentro de sus reglas, a la vez que produce esa nueva vida como un hecho social fundamentado en el saber científico externo al saber jurídico. Es por esto que podemos sostener la existencia de una nueva modalidad de la vida afirmada por la ciencia y producida por el derecho.

10. Sentencia de Corte de Apelaciones de Santiago, considerando undécimo. 


\section{La vida performativa}

En la producción que despliega el dispositivo judicial existe no sólo un proceso de traducción del entendimiento de lo normal y lo patológico desde el lenguaje científico hacia el lenguaje jurídico, sino además una carga normativa en el momento en que la Corte define que la evidencia de circuitos neuronales alterados (explícitamente mostrados vía RMN) da lugar a un comportamiento humano excusable, con lo que va más allá de lo establecido por el saber científico. La situación es distinta a la establecida por la doctrina penal, que alude a casos de privación total de la razón por causas circunstanciales (y eminentemente temporales) como la embriaguez como razón jurídica del atenuante del artículo 11 número 1 del Código Penal. Lo que se atenúa ahora, mediante la apelación a una técnica de mostramiento neuronal, es una condición permanente que se sanciona como forma de vida excusada (la enfermedad de Marchiafava-Bignami) y no un estado temporal (la embriaguez), atribuyendo de esta manera un poder performativo al saber científico por la vía de la producción judicial.

Es por ello que la noción de «vida normal» presenta una mutación a partir de una sanción judicial, pues se le atribuye a una nueva configuración neuronal efectos gestacionales. Cuando el tribunal valora a quien padece la EMB como un sujeto «parcialmente normal», al considerar su enfermedad como un atenuante, lo produce performativamente como un sujeto al que se le aplica el derecho de manera diferenciada. Como vimos, esa «aplicación normal del derecho» se puede realizar sólo después del proceso de traducción desde el dispositivo científico del saber experto al lenguaje del derecho.

La modalidad de vida es nueva porque se produce performativamente en cada práctica en que el dispositivo judicial, en alianza con el científico, fija un nuevo límite de conducta (y responsabilidad) para la vida humana. En nuestro caso, hablamos de un conductor ebrio cuya responsabilidad frente a un hecho ilícito es reducida no tanto porque su conducta particular haya sido atenuada (como en el caso estándar), sino porque a partir de un proceso de traducción de saberes se constituye como forma de vida que en sí misma (debido a la EMB y evidenciada por RMN) se considera excusada.

\section{Referencias}

Agamben, Giorgio (2008). El reino y la gloria: Una genealogía teológica de la economía y del gobierno. Buenos Aires: Adriana Hidalgo.

Aggarwal, Neil (2009). «Neuroimaging, culture, and forensic psychiatry». Journal of the American Academy of Psychiatry Law, 37 (2): 239-244. Disponible en http:// bit.ly/2kCogJF.

Aharoni, Eyal, Chadd Funk, Walter Sinnott-Armstrong y Michael Gazzaniga (2008). «Can neurological evidence help courts assess criminal responsibility? 
Lessons from law and neuroscience». Annals of the New York Academy of Sciences, 1.124: 145-16o. DOI: 10.1196/annals.1440.007.

Aharoni, Eyal, Gina Vincent, Carla Harenski, Vince Calhoun, Walter SinnottArmstrong, Michael Gazzaniga y Kent Kiehl (2013). «Neuroprediction of future rearrest». PNAS, 110 (15): 6.223-6.228. DOI: 10.1073/pnas.1219302110.

Arbelález, Andrés, Adriana Pajón, Dagoberto Cabrera y Luis Guillermo Palacio (2003). «Neuroimagen en la enfermedad de Marchiafava Bignami». Acta Neurológica Colombiana, 19 (3): 156-159. Disponible en http://bit.ly/2kEVaJK.

Armstrong, David (1983). Political anatomy of the body: Medical knowledge in Britain in the twentieth century. Cambridge: Cambridge University Press.

-. (1995). «The rise of surveillance medicine». Sociology of Health \& illness, 17 (3): 393-404. DOI: 10.1111/1467-9566.ep10933329.

Arney, William Ray y Bernard Bergen (1984). Medicine and the management of living: Taming the last great beast. Chicago: University of Chicago Press.

Arrigo, Bruce (2007). «Punishment, freedom, and the culture of control: The case of brain imaging and the law». American Journal of Law \& Medicine, 33: 457-482. DOI: $10.1177 / 009885880703300213$.

Catley, Paul y Lisa Claydon (2015). "The use of neuroscientific evidence in the courtroom by those accused of criminal offenses in England and Wales». Journal of Law and the Biosciences, 2 (3): 510-549. DOI: 10.1093/jlb/lsvo25.

CAMARgO, Ricardo y Nicolás RiED (2016). «Towards a genealogy of pharmacological practice». Medicine, Health Care and Philosophy, 19 (1): 85-94. DOI: $10.1007 /$ s11019-015-9648-3.

Castro, Edgardo (2011a). Diccionario Foucault, temas, conceptos y autores. Buenos Aires: Siglo XXI.

-. (2011b). Lecturas foucaultianas: Una historia conceptual de la biopolítica. La Plata: Unipe.

Clarke, Adele, Janet Shim, Laura Mamo, Jennifer Ruth Fosket y Jennifer Fishman (2003). «Biomedicalization: Technoscientific transformations of health, illness, and US biomedicine». American Sociological Review, 68 (2): 161-194. Disponible en http://bit.ly/2kFGAlo.

Cousiño MAC Iver, Luis (1992). Derecho penal chileno. Santiago: Jurídica.

Engelhardt, Tristram, Stuart Spicker y Bernard Towers (editores) (1979). Clinical judgment: A critical appraisal. Dordrecht, Londres: Reidel.

Etcheberry, Alfredo (1970). Derecho penal. Tomo 1. Santiago: Jurídica.

Feinstein, Alvan (1967). Clinical judgment. Baltimore: Williams \& Wilkins.

Foucault, Michel (2010). «La verdad y las formas jurídicas». En Obras esenciales. Madrid: Paidós.

-. (2014). Obrar mal, decir la verdad: La función de la verdad en la justicia. Buenos Aires: Siglo XXI. 
Franklin, Sarah (1995). «Life». En Warren Reich (editor), The encyclopedia of bioethics: Revised edition. Nueva York: Simon \& Schuster.

-. (2000). «Life itself: Global nature and the genetic imaginary». En Sarah Franklin, Celia Lury y Jackie Stacey (editores), Global nature, global culture. Londres: Sage.

-. (2005). «Stem cells R Us: Emergent life forms and the global biological». En Aihwa Ong y Stephen Collier (editores), Global assemblages: Technology, politics, and ethics as anthropological problems. Malden: Blackwell.

Garrido Montt, Mario (2007). Derecho penal: Parte general. Tomo 2. Santiago: Jurídica.

Hillbom, Matti, Pertti Saloheimo, Shinsuke Fujioka, Zbigniew Wszolek, Seppo Juvela y Maurizio Leone (2014). «Diagnosis and management of MarchiafavaBignamidisease: A review of CT/MRI confirmed cases». Neurology, Neurosurgery \& Psychiatry, 85 (2): 168-173. DOI: 10.1136/jnnp-2013-305979.

Labatut, Gustavo (1976). Derecho penal. Tomo 1. Santiago: Jurídica.

Lemke, Thomas, Monica CASper y Lisa Jean Moore (2011). Biopolitics: An advanced introduction. Nueva York: NYU Press.

Mateo Ayala, Eladio José (2006). Los antecedentes de la eximente de anomalía o alteración psíquica. Madrid: Dykinson.

Nealon, Jeffrey (2008). Foucault beyond Foucault. Stanford: Stanford University Press.

Novoa Monreal, Eduardo (1960). Curso de derecho penal chileno. Tomo 1. Santiago: Jurídica.

Politoff, Sergio, Jean Pierre Matus y María Cecilia Ramírez (2014). Lecciones de derecho penal: Parte general. Santiago: Jurídica.

ReID, Julian (2011). «Life struggles: War, discipline and biopolitics in the thought of Michel Foucault». En Michael Dillon y Andrew Neal (editores), Foucault on politics, security and war. Londres: Palgrave Macmillan.

Revel, Judith (2008). Diccionario Foucault. Buenos Aires: Nueva Visión.

Rose, Nikolas (1985). The psychological complex: Psychology, politics and society in England, 1869-1939. Londres: Routledge and Kegan Paul.

-. (1989). Governing the soul: The shaping of the private self. Londres: Routledge.

Rose, Nikolas (1996). Inventing our selves: Psychology, power, and personhood. Nueva York: Cambridge University Press.

-. (1999). Powers of freedom: Reframing political thought. Cambridge: Cambridge University Press.

-. (2007). Powers of freedom: Reframing political thought. Cambridge: Cambridge University Press.

Rose, Nikolas y Peter Miller (2008). Governing the present: Administering economic, social and personal life. Cambridge: Polity. 
Rose, Nikolas y Joelle Aвi-RAched (2013). Neuro: The new brain sciences and the management of the mind. Princeton: Princeton University Press.

STARR, Paul (1982). The social transformation of American medicine. Nueva York: Basic Books.

TAYlor, Dianna (2011). Michel Foucault, key concepts. Durham: Acumen Publishing Limited.

\section{Reconocimiento}

Este trabajo presenta resultados del proyecto Fondecyt Regular núm. 1170940, titulado «Biopolítica molecular: Dimensiones políticas, jurídicas y éticas de los marcadores biológicos», en el que el profesor Camargo es investigador responsable.

\section{Sobre los autores}

Ricardo Camargo Brito es abogado. Licenciado en Ciencias Jurídicas y Sociales por la Universidad de Chile. Máster en Estudios Internacionales por la Universidad de Otago, Nueva Zelanda. Máster en Ciencia Política por la Universidad de Chile y doctor en Ciencia Política por la Universidad de Sheffield, Reino Unido. Profesor asociado en la Facultad de Derecho de la Universidad de Chile. Su correo electrónico es rcamargo@derecho.uchile.cl.

Nicolás Ried Soto es licenciado en Ciencias Jurídicas y Sociales por la Universidad de Chile y doctorante del Doctorado en Filosofía, mención en Estética y Teoría del Arte, de la Facultad de Artes de la Universidad de Chile. Su correo electrónico es nicolasried@gmail.com. 


\title{
REVISTA CHILENA DE DERECHO Y TECNOLOGÍA
}

La Revista de Chilena de Derecho y Tecnología es una publicación académica semestral del Centro de Estudios en Derecho Informático de la Facultad de Derecho de la Universidad de Chile, que tiene por objeto difundir en la comunidad jurídica los elementos necesarios para analizar y comprender los alcances y efectos que el desarrollo tecnológico y cultural han producido en la sociedad, especialmente su impacto en la ciencia jurídica.

\author{
EDITOR GENERAL \\ Daniel Álvarez Valenzuela \\ (dalvarez@derecho.uchile.cl) \\ SITIO WEB \\ rchdt.uchile.cl \\ CORREO ELECTRÓNICO \\ rchdt@derecho.uchile.cl \\ LICENCIA DE ESTE ARTÍ́CULO \\ Creative Commons Atribución Compartir Igual 4.0 Internacional
}

\begin{abstract}
y
La edición de textos, el diseño editorial

y la conversión a formatos electrónicos de este artículo

estuvieron a cargo de Tipográfica

(www.tipografica.cl).
\end{abstract}

